\title{
PROJETO PROFISSIONAL E DIRETRIZES CURRICULARES DO SERVIÇO SOCIAL NO BRASIL: PERSPECTIVAS POLITICO-PEDAGÓGICAS
}

\author{
SOCIAL SERVICES IN BRAZIL: PROFESSIONAL PROJECT AND SYLLABUSES. POLITICAL AND \\ PEDAGOGICAL PERSPECTIVES
}

\author{
Cleusa Santos \\ Pós-Doutora em Serviço Social. Universidade Federal \\ do Rio de Janeiro \\ Sandra de Faria \\ Pós-Doutora em Serviço Social. Pontifícia \\ Universidade Católica de Goiás
}

\author{
Contato \\ Cleusa Santos \\ E-mail: cleusasantos@uol.com.br
}

\section{RESUMO}

Este texto analisa as diretrizes curriculares para os cursos de Serviço Social no Brasil. Ressalta o desenvolvimento histórico-social das diretrizes curriculares, evidenciando o caráter político da profissão. Em relação a essa dimensão, a formação profissional vincula-se ao projeto coletivo da profissão.

Palavras-chave: Supervisão; Formação profissional; Dimensão política; Diretrizes curriculares.

\begin{abstract}
The present text analyses the syllabuses of the social services courses in Brazil. It highlights the historical and social development of the syllabuses and their political aspect. It shows how this is linked to the professional training of the social workers.
\end{abstract}

Keywords: Supervision; Professional training; Political aspects; Syllabuses.

\section{INTRODUÇÃO}

\section{Prólogo à dimensão coletiva do projeto profissional}

\begin{abstract}
A problemática da gênese e do desenvolvimento do Serviço Social brasileiro está intimamente ligada à sua própria legitimidade social. Sua história registra que, nas décadas posteriores a 1979, na busca dessa legitimidade, segmentos da categoria empenharam-se na procura da construção de um projeto profissional, na explicação dos seus nexos por meio da produção do conhecimento acadêmico e na redefinição de uma agenda socioprofissional.

Nessa direção, lamamoto ${ }^{1}$ ressalta que a ruptura com a herança conservadora requer a interação entre o aprofundamento teórico rigoroso e a prática renovada, politicamente definida - elemento decisivo para superar as contrafações ideológicas incorporadas pela profissão em sua evolução histórica: o voluntarismo, a prática rotineira e burocratizada, as tendências empiricistas, o alheamento central do modo de vida do povo, o desconhecimento do saber popular etc.
\end{abstract}


Afirma ainda que entendida em uma dimensão processual, essa ruptura tem como pré-requisito que o assistente social aprofunde a compreensão das implicações políticas de sua prática profissional, reconhecendo-a como polarizada pela luta de classes. Em outros termos, o profissional é mobilizado na implementação de políticas sociais que trazem no seu bojo interesses divergentes e antagônicos que o exercício profissional, contraditoriamente, reproduz, já que tende a ser cooptado por uma das forças em confronto. Essa compreensão é básica para tornar possível que o assistente social faça uma opção teórico-prática por um projeto coletivo de sociedade e supere as ilusões de um fazer profissional que "paire acima da história. Isso implica, por sua vez, o enriquecimento do instrumental científico de análise da realidade social e o acompanhamento atento da dinâmica conjuntural" conforme analisa lamamoto".

As análises de Netto ${ }^{2,3,4,5}$ compreendem de forma madura a consolidação da vertente de ruptura com o conservadorismo e sua importância para a renovação teórico-cultural da profissão. Segundo o autor, na década de 1980, consolidou-se, no plano ideopolítico, a ruptura com o histórico conservadorismo do Serviço Social. Ao que se acrescenta que, passadas as últimas décadas, a maioridade do Serviço Social ganhou maior densidade, volume e complexidade nas ramificações e tendências de sua elaboração teórica. Além disso, a vertente de ruptura com o conservadorismo tem-se afirmado como uma linha de força manifesta no contexto da renovação do Serviço Social brasileiro, ao confluir a influência da tradição marxista e a direção social estratégica do projeto profissional ético-político.

Conforme $\mathrm{Netto}^{6}$, nas condições contemporâneas, uma categoria profissional jamais é um bloco identitário ou homogêneo - é, sempre, sob todos os prismas, um conjunto diferenciado e em movimento. Uma direção consolidada é aquela que, sintonizada com as tendências sócio-históricas mais significativas, circunscreve o espaço de enfrentamento das diferenças em função de objetivos que se fazem reconhecidos como legítimos e pertinentes; nessa ótica, aliás, é apenas em face de uma direção determinada que as diferenças profissionais adquirem sentido.

Posto isso, compreende-se que a direção social dimanada do projeto ético-político profissional adquire inteligibilidade se pensada quanto aos compromissos e vínculos da categoria com os movimentos políticos, civis e sociais, para além daqueles derivados dos espaços sócio-ocupacionais do assistente social. Nessa perspectiva, ganham relevo as produções sobre o Serviço Social pensado nos marcos do contexto latino-americano do pós-1970 e seus antecedentes. As dimensões substantivas dessa trajetória são fundamentais para melhor captar as mediações profissionais e sociais que, desde o Movimento de Reconceituação Latino-Americano (1965-1975), demarcam o processo de renovação do Serviço Social brasileiro. 
Desse contexto, são extraídas as reflexões sobre as Diretrizes Curriculares Nacionais, de 1996, defendidas pela Associação Brasileira de Ensino e Pesquisa em Serviço Social (ABEPSS) para a formação profissional, com base também em investigações sobre a trajetória do Serviço Social no Brasil, suas particularidades e implicações, priorizando a perspectiva histórica e as lentes teórico-metodológicas da tradição marxiana. Nessa direção, procura-se resgatar as principais contribuições e prioridades do debate sobre a formação (na sua dimensão pedagógica, socioeducativa e técnico-operativa) para vincular a relação dos instrumentos da ciência - como é o caso da pesquisa - ao processo de formação profissional.

\section{TRAJETÓRIA SOCIOPROFISSIONAL DO SERVIÇO SOCIAL E INTENÇÃO DE RUPTURA}

$\mathrm{N}$ a sociedade capitalista moderna, o pensamento social conservador, fundado no cientificismo positivista, direcionou o desenvolvimento do sistema de ensino superior, ligando as especializações, as profissões e a produção de conhecimento às relações sociais particulares e a uma função social imediata. Com domínio amplo e sólido nas Ciências Sociais e Humanas, o pensamento social conservador, como demonstra Escorsim $\mathrm{Netto}^{7}$, influiu e influi na organização acadêmica e científica do conhecimento produzido nas várias áreas de especialização.

Segundo essa tradição teórica, o que funda uma profissão não são as relações de produção e reprodução da vida social, mas a função social e o estatuto profissional, resultantes de um saber científico e prático, de um ideal de competência fundado na formação/especialização. Sob esse enfoque, as disciplinas, as instituições profissionais e a ideologia do profissionalismo surgem como respostas às necessidades sociais/individuais, contribuindo para a regulação e o controle social.

Uma profissão significa, idealmente, realização pessoal, reserva e monopólio de mercado de trabalho para a realização de atividades, emprego estável e elevado reconhecimento. Uma profissão é a expressão de valores de ordem ética, com configurações morais e/ou culturais. Assim, na ótica funcionalista, o que caracteriza e explica uma profissão é uma estrutura modelar que privilegia a relação profissional - cliente, tendo em vista promovê-la, reconhecê-la e regulamentá-la.

No nível analítico, o significado mais profundo do pensamento conservador passa por uma construção lógica e ideal do fenômeno das profissões e, embora sinalize que é necessário não confundir tendências efêmeras, de curto prazo, com tendências de longo prazo, e mudanças cíclicas com mudanças progressivas e lineares, estrutura os seus argumentos sob a ótica da profissão como ocupação estável e organizada, campo de competências e monopólio de especialidades, alicerçando, a partir da formalização de controles profissionais e de órgãos disciplinadores, uma ideologia do profissionalismo, que formaliza os conflitos e as contradições em uma ética da competência.

A partir da crítica a essa compreensão e suas ramificações na sociologia das profissões, formulou-se uma abordagem sócio-histórica ao papel conservador desempenhado pelo Serviço Social, que legitimava o Estado burguês e elidia a luta de classes, destacando, no processo de renovação da profissão, os vetores, as tendências e as linhas de forças que conduziram à inserção da categoria no movimento vivo da sociedade brasileira, nas lutas ideológicas.

A vertente que perspectivou romper com o conservadorismo, como uma das tendências que se afirmaram no âmbito da categoria, adotou por direção a articulação dos interesses corporativos com a defesa das reivindicações, interesses e necessidades sociais da classe trabalhadora. Do ponto vista do debate profissional, formula uma abordagem crítica ao tratamento linear, focalista e a-histórico das profissões. Foram abordagens de diferentes autores, que desmistificam a ênfase atribuída à fixação rígida das especializações do saber e as promessas de prestígio e "status" intelectual.

Essa abordagem, ao enfatizar as relações societárias capitalistas, ampliou, em um primeiro momento, as análises sobre o contexto em que se inseria o processo de profissionalização do Serviço Social, e em sua esteira, abriu condições para erodir a base do conservadorismo na profissão e desencadear o processo que visou à instauração de novos padrões intelectuais e profissionais no Serviço Social brasileiro.

Na perspectiva de teoria social de Marx, não é possível prescindir da história e construir, abstratamente, as categorias analíticas sem estabelecer a sua condição determinante, a sua particularidade e o seu conteúdo heurístico, premissas que indicam os caminhos para que se compreendam as determinações e as determinidades produzidas social e historicamente.

Marx8 demonstrou como a fixação imediata de uma direção é decisiva para toda ciência histórica e social em geral, e não apenas para a economia política: em toda ciência histórica e social em geral, é preciso ter sempre em conta, a propósito do curso das categorias econômicas, que o sujeito, neste caso a sociedade burguesa moderna, está dado tanto na realidade efetiva como no cérebro; que as 
categorias exprimem, portanto, formas de modos de ser, determinações de existência, frequentemente aspectos isolados dessa sociedade determinada, desse sujeito, e que, por conseguinte, essa sociedade de maneira nenhuma se inicia, inclusive do ponto de vista científico, somente a partir do momento em que se trata dela como tal.

O estudo do fenômeno da origem, organização, legalização e legitimação das profissões relaciona-se, geneticamente, ao princípio fundamental da divisão social e hierárquica do trabalho que, no capitalismo, predominou de forma sistemática e generalizada. E se é impossível dar o correto tratamento a essa questão de forma breve, vale, no entanto, observar que, sem dúvida, os problemas do processo de trabalho estão implicados à totalidade das relações de produção que formam a estrutura econômica da sociedade capitalista, a base real sobre a qual se levanta uma superestrutura jurídica e política, e à qual correspondem formas sociais determinadas de consciência, nos termos de Marx ${ }^{8}$.

No entanto, Marx não negligencia o caráter natural da existência humana, o metabolismo entre o homem e a natureza, para apreender a transformação peculiar que o modo de produção capitalista opera no processo de trabalho. Antes, investiga o sistema de metabolismo social do capital, como processo de produção capitalista, orientado para a expansão e compelido para a acumulação, analisa Mészáros, apud Antunes ${ }^{9}$.

Enuncia a subordinação do trabalho ao capital, da produção de coisas úteis e de valores de uso ao comando do valor de troca, conduzido por um sistema de acumulação, de valorização, reprodução e ampliação do circuito produtivo capitalista. Os enfoques teóricos que ignoram o processo de trabalho capitalista como um processo de acumulação e valorização do capital tendem a considerar a divisão social do trabalho como expressão da divisão técnica, da especialização moderna entre ramos, ofícios, ocupações e profissões, com apreciações especulativas quanto ao seu valor e suas formas.
Nesse nível de abstração, evidentemente, nada se pode saber sobre a divisão do trabalho, exceto a trivial e apologética conclusão de que, sendo "universal", cada uma de suas manifestações é, provavelmente, inevitável. Desnecessário dizer que precisamente esta é a conclusão que a sociedade burguesa prefere, analisou Braverman ${ }^{10}$ em sua obra clássica.

$\mathrm{Na}$ sociedade capitalista, o trabalho está posto sob condições sociais específicas, e essas são determinantes da divisão social e técnica. Além disso, a diferenciação técnica é também parte do processo de produção de mercadorias e processo de valorização. Como formula Marx ${ }^{11}$ :

O capitalista, ao transfor-
mar dinheiro em mercado-
rias, que servem de matérias
constituintes de um novo
produto ou de fatores do
processo de trabalho, ao
incorporar força de trabalho
viva à sua objetividade
morta, transforma valor,
trabalho passado, objetivado,
morto em capital, em valor
que se valoriza a si mesmo, um
monstro animado que
começa a trabalhar como se
tivesse amor no corpo."


Esses pressupostos da análise marxiana $\mathrm{e}$ marxista crivam medularmente a análise histórica do Serviço Social como uma especialização do trabaIho coletivo e interditam as elaborações que operam com a imediata e simples identificação fenomênica dos aspectos (protoformas) que constituem a gênese da profissão com o conhecimento histórico do processo de institucionalização profissional.

Assim, a legitimidade social e as competências profissionais convertem-se em questões centrais enfrentadas pela categoria no Brasil, que se articulou e passou a lutar por um projeto profissional de ruptura com o conservadorismo e seus efeitos teóricos, políticos e formas de intervenção profissional. Configura-se um movimento profissional não homogêneo, mas mobilizador de interesses coincidentes, quando contraposto aos interesses dos grupos tradicionais, que explora novos caminhos no sentido de dotar o Serviço Social de uma legitimidade social mais substantiva e abrangente. Esse movimento foi impulsionado, reconhecidamente, pelas tendências mais críticas e comprometidas com a trajetória do Serviço Social na América Latina.

A história recente do Serviço Social brasileiro atesta a relevância da sua organização política e o papel protagônico das entidades de representação da categoria na trajetória renovadora do pós-1970. $\mathrm{Na}$ história da profissão, há vários exemplos que demonstram as prioridades assumidas pelas entidades de representação, a extinta Associação Nacional Sindical de Assistentes Sociais (ANAS) e sindicatos, Associação Brasileira de Ensino e Pesquisa em Serviço Social (ABESS) e as unidades acadêmicas, Conselho Federal de Serviço Social (CFESS) e os conselhos regionais e Executiva Nacional de Estudantes de Serviço Social (ENESSO) e os centros acadêmicos. Destacam-se a relação da agenda dos debates profissionais com o movimento sindical e as lutas gerais da sociedade; os eixos e temas dos eventos, conteúdos contextualizadores da inserção da categoria na luta mais ampla da classe trabalhadora; e, sobretudo, a reivindicação e a defesa da democracia e da política como necessidades vitais para a organização política da categoria.

Essa inflexão resultou da ação de um conjunto de forças que optou por um projeto profissional vinculado ao processo de construção de uma nova ordem societária sem dominação - exploração de classe, etnia e gênero (Código de Ética Profissional - Princípios) e adotou como componente de direção social estratégica o redimensionamento da agenda socioprofissional consoante com o projeto profissional e societário que defendia. Esse redimensionamento da agenda clivou as questões que afligiam e preocupavam os pesquisadores compromissados com a perspectiva crítica, com a ruptura, com o conservadorismo e seus aportes culturais.

O novo na profissão é o processo que enlaça a emergência de um Serviço Social com a afirmação de outro perfil profissional, legitimado a partir da crítica às vertentes que defendem a individualização dos problemas sociais e buscam o controle e a coesão social.

Enlace construído entre a profissão, os profissionais e o inseparável problema da consciência de classe, entre a experiência real de organização política da categoria e o desenvolvimento de uma consciência de classe que questiona a consciência corporativista que focaliza o "status" e os privilégios legais implicados em vantagens econômicas. Não se trata de uma homogeneidade no perfil da categoria, mas de um processo histórico revelador de heterogeneidades complexas e intrínsecas relações de classes que atravessaram e atravessam a profissão.

\section{FORMAC̣ÃO E PROFISSÃO: O CONTEXTO DAS INTER-RELAC̄ÕES SÓCIO-HISTÓRICAS}

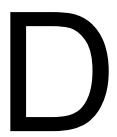
e acordo com as reflexões anteriores, entende-se que o desenvolvimento profissional é um fenômeno histórico de caráter contraditório, sendo a atividade profissional determinada pela maneira como se organiza a sociedade e pelo resultado da atuação da categoria profissional.

Nesse sentido, tratar a dimensão política da relação formação e profissão no contexto histórico é reconhecer as dificuldades apresentadas na conjuntura, considerando tanto as mudanças estruturais do sistema capitalista, suas estratégias políticas, e os impactos na profissão quanto as reformas modernizantes e neoliberais, principalmente as financeiras, iniciadas no Brasil no final dos anos 1980 e que tiveram impactos no mundo do trabalho. Alguns exemplos desses impactos podem ser encontrados no cerco aos direitos adquiridos pelos trabalhadores, redução dos salários, dos encargos trabalhistas, assim como nos gastos dos empregadores e do Estado, reduzindo o número de empregos, flexibilizando e precarizando o mercado de trabalho.

Tais impactos redesenham alguns eixos nucleares da formação profissional, particularmente aqueles voltados para o ensino da prática profissional, como é o caso da supervisão, desafiando a orientação política de uma prática profissional vinculada com a perspectiva de classe, da cidadania e 
com o aprofundamento da democratização da vida social contribuindo para o processo de construção de um novo bloco histórico na sociedade, com a hegemonia daqueles que criam a riqueza e dela não se apropriam, como problematiza lamamoto ${ }^{12,13,14,15} \mathrm{em}$ diferentes textos.

Para compreender a dimensão política das diretrizes curriculares, no Serviço Social, segundo os organismos políticos da categoria profissional (ABEPSS, o CFESS/CRESS e a ENESSO), é preciso afirmar a construção de um perfil profissional resultante de sua adesão às diretrizes curriculares que orientam o projeto pedagógico dos cursos de Serviço Social que se materializa nessas legislações. A partir de 2001, o novo currículo implantado em todas as unidades de ensino define o estágio supervisionado como atividade curricular obrigatória e destaca seu significado no processo de formação profissional do assistente social.

O currículo em vigência supõe a formação de um profissional que atue nas expressões da questão social, formulando e implementando propostas para seu enfrentamento, por meio de políticas sociais públicas, empresariais, de organizações da sociedade civil e movimentos sociais; seja dotado de formação intelectual e cultural generalista crítica, competente em sua área de desempenho, disponha de capacidade de inserção criativa e propositiva, no conjunto das relações sociais e no mercado de trabalho e seja comprometido com os valores e princípios norteadores do Código de Ética do Assistente Social.

É claro que os ideais em torno dos quais o projeto profissional se articula são aqueles comprometidos com os interesses históricos das classes trabalhadoras e reafirmam, por meio do Código de Ética de 1986, a dimensão política da prática profissional. Percebe-se que para explicar a dimensão política desses ideais é necessário fazer uma digressão história da ABEPSS, pois o projeto profissional em curso é a conclusão de um processo histórico anterior à década de 1990. Neste sentido, destaca-se, do ponto de vista dos currículos, que os anos 1970 evidenciam os efeitos do Movimento de Reconceituação Latino Americano (que permitiu avançar em direção à superação do conservadorismo).

Muitos estudiosos apontam a década de 1970 como o início de um processo que deu origem ao currículo vigente. Destacam como principais representantes a ABEPSS e CEDEPSS que possibilitaram a democratização do debate e a socialização do pensamento das escolas e dos profissionais. Assim, o novo currículo se encontra intimamente relacionado com a sua finalidade de atuar na dinâmica das relações entre o Estado e a sociedade civil exigindo, portanto, funções investigativas ante a realidade.
Recorde-se que foi por intermédio de uma ampla pesquisa sobre formação profissional que o novo currículo de 1984 foi estruturado. Ele expressou um processo de renovação tendo como elementos constitutivos a produção teórica, a organização política da categoria, as reflexões éticas e, não menos relevante, a ampliação das pesquisas. Tudo isso possibilitou a superação do antigo currículo.

Naquela fase de grave crise econômica e rearticulação da sociedade civil, a necessidade de revisão acerca dos objetivos, conteúdo e da função social da formação profissional era imperativa. Por isso a identificação do Serviço Social como uma atividade inscrita na divisão sociotécnica do trabalho e historicamente determinada; o entendimento de que o fundamento da profissão é a compreensão crítica e não estática da realidade social; o compromisso político com a classe trabalhadora e a legitimação da prática.

Sobre essa legitimação, destacamos que as mudanças nos processos de legitimação profissional acompanham as transformações sociais, econômicas e políticas da sociedade, pois a dimensão política do Serviço Social não pode ser tomada como relação de exterioridade. Ela é dotada de objetividade, ou seja: a profissão é uma especialização do trabalho social inscrita na divisão social e técnica do trabalho, quando se considera a determinação sócio-histórica da estrutura econômica da sociedade burguesa. Por outro lado, sua subjetividade se revela no desenvolvimento das condições que possibilitam uma vinculação consciente entre o nível técnico e o nível político expresso na requisição de um assistente social como um tipo particular de intelectual.

Se nos anos 1970 a reconceituação tornou-se o marco para a tentativa de ruptura do Serviço Social crítico com o Serviço Social tradicional - propiciando um amplo e vigoroso debate em torno das perspectivas teórico-ideológicas que sustentavam a formação profissional até os anos de 1970 -, os anos 1980, época de redemocratização da sociedade brasileira, serviram de base para a construção de uma nova Proposta de Diretrizes Gerais para o Curso de Serviço Social, reorientando, assim, a formação profissional dos assistentes sociais.

Observou lamamoto ${ }^{14}$ que, naquelas duas décadas, o Serviço Social deu um salto qualitativo em sua autoqualificação, uma vez que houve alterações no ensino universitário, expansão do acervo bibliográfico, produções científicas e aumento das publicações do Serviço Social. Já nos anos 1990, a categoria conseguiu maior expressão com pesquisadores reconhecidos pelas agências de fomento: ampliou-se o debate em torno das políticas públicas, possibilitando o adensamento e o fortalecimento de seu autorreco- 
nhecimento. Dessa forma, a transição para o currículo dos anos 1990 exigiu dos organismos representativos da categoria profissional uma maior aproximação com a intervenção (prática) profissional.

Além disso, impôs-se uma revisão crítica dos elementos que levaram ao teoricismo, possibilitando uma "apropriação teórico-metodológica no campo das grandes matrizes do pensamento social [que] permitiria a descoberta de novos caminhos para o exercício profissional"; ao politicismo, por meio do "engajamento político nos movimentos organizados da sociedade e nas instâncias de representação da categoria e do tecnicismo - cujo aperfeiçoamento técnico-operativo mostra-se como uma exigência para uma inserção qualificada do profissional no mercado de trabalho".

Sob tais condições, a dimensão política deve estar articulada aos interesses dos setores majoritários da sociedade (a classe trabalhadora). O projeto ético-político profissional exige do profissional um posicionamento firme na defesa do compromisso com a autonomia, a emancipação e a plena expansão dos indivíduos sociais no sentido da liberdade como valor ético central. Entretanto, a concretização desses princípios requer fundamentos teóricos e metodológicos capazes de instrumentalizar o profissional para a análise da realidade social.

$\mathrm{O}$ essencial é compreender que o trabalho e a questão social, eixos centrais das diretrizes curriculares da formação profissional, não resultam do acaso. Eles constituem uma orientação ideológica e política voltada para um projeto social que assinala a necessidade de uma direção social (ético-política) para o projeto pedagógico das escolas de Serviço Social ao qual o ensino da prática está vinculado. Nesse sentido, formam-se os aspectos ideopolíticos dos eixos centrais da formação profissional.

\section{CONSIDERAC̣ÕES FINAIS}

$\mathrm{E}$

ntende-se que a questão social impõe um selo político ao fazer profissional. Constitui-se na contradição fundamental do modo de produção capitalista que está fundada na produção coletiva e na apropriação privada da riqueza social. Já o trabalho é a categoria central para entender a constituição da vida social e da profissão.

Nesse sentido, a compreensão da realidade social como processo histórico, desenvolvido fundamentalmente pelas lutas de classe, com centralidade na categoria trabalho e nas contradições capital/trabalho, reproduzindo tanto a sua dinâmica e estrutura (positividade) quanto contendo sua negação, põe-se como condição para os assistentes sociais e Serviço Social, para a formação, a produção de conhecimentos e o exercício profissional.

Reconhecer, portanto, o caráter da pesquisa e do espírito investigativo como condições essenciais ao exercício profissional invoca um duplo desafio para a formação do assistente social: entender a gênese da questão social e as situações particulares e fenômenos singulares que são confrontados no mercado de trabalho. Afinal, desde meados dos anos 1980, emergem ações no sentido de concretizar espaços, como é o caso da criação do Fórum de Supervisores, para "se constituir enquanto um fórum importante de organização política dos profissionais para o enfrentamento das questões relativas à formação profissional, em especial àquelas vinculadas ao Estágio como um momento privilegiado do "ensino da prática", analisa Santos ${ }^{16}$.

Mediar essa relação que vai além dos limites acadêmicos parece ser um dos grandes desafios das entidades organizativas, particularmente da Associação Brasileira de Ensino e Pesquisa em Serviço Social. Nesse contexto, os avanços significativos no âmbito da direção da ABEPSS se expressam nos resultados da pesquisa realizada sobre as Diretrizes Curriculares e na elaboração da política nacional de estágio (PNE) $)^{17}$, possibilitando "balizar os processos de mediação teórico-prática na integralidade da formação profissional do assistente social". 


\section{Referências}

1. lamamoto MV. A Renovação Conservadora no Serviço Social. Ensaios Críticos. São Paulo: Cortez; 1992.

2. Netto JP. Ditadura e Serviço Social. Uma Análise do Serviço Social no Brasil pós - 64. São Paulo: Cortez; 1991.

3. Netto JP. Serviço Social e tradição marxista. Serv Soc \& Sociedade, 1989 abr; 30 Ano X: 89-91.

4. Netto JP. A construção do projeto ético-político do Serviço Social frente à crise contemporânea. Capacitação em Serviço Social e Política Social. Módulo I. 1999 CEAD/UNB.

5. Netto JP. O Movimento de Reconceituação: 40 anos depois. Serv Soc \& Sociedade 2005; (84).

6. Netto JP. Transformações societárias e Serviço Social - notas para uma análise prospectiva da profissão no Brasil. Serv Soc \& Sociedade. 1996; (50).

7. Netto LE. O conservadorismo clássico: elementos de caracterização e crítica. São Paulo: Cortez; 2011.

8. Marx K. Para a Crítica da Economia Política. Tradução Edgard Malagodi. São Paulo: Abril Cultural; 1982. (Os Economistas).

9. Antunes R. Os sentidos do Trabalho. Ensaio sobre a afirmação e a negação do trabalho. São Paulo: Boitempo; 1999.

10. Braverman H. Trabalho e Capital Monopolista. A Degradação do Trabalho no Século XX. Rio de Janeiro: Guanabara; 1987.

11. Marx K. O Capital: crítica da economia política. São Paulo: Nova Cultura; 1988. (Os economistas).

12. lamamoto MV. O trabalho do Assistente Social frente às mudanças do padrão de acumulação e de regulação social. Capacitação em Serviço Social e Política Social - Crise contemporânea, questão social e Serviço Social, módulo 01. Brasília: CFESS/ABEPSS/CEAD/UNB; 1999.

13. lamamoto MV. O significado dos Serviços Sociais. Relações Sociais e Serviço Social no Brasil. São Paulo: Cortez-Celats; 1983.

14. lamamoto MV. Serviço social brasileiro e a articulação latino-americana. Rev Temp/Assoc Bras de Ens e Pesq. em Serviço Social. 2004 jan/jul. 2003; 7 Ano IV.

15. lamamoto MV. O Serviço Social na contemporaneidade: trabalho e formação profissional. São Paulo: Cortez; 1998.

16. Santos C. As diretrizes curriculares da ABEPSS: desafios atuais da supervisão para a concretização do perfil profissional. Serv. Soc. \& Saúde [periódicos na Internet]. 2011 [acesso em 06 dez. 2015]; 9:23-35. Disponível em: www.bibliotecadigital.unicamp.br/document/?down=47808

17. Associação Brasileira de Ensino de Serviço Social. Política Nacional de estágio da Associação Brasileira de Ensino e Pesquisa em Serviço Social, 2009. Disponível em http://www.abepss.org.br/files/politica_nacional_estagio.pdf

18. Abramides MBC, Socorro, MRC. O novo sindicalismo e o serviço social. Trajetória e Processos de Luta de uma Categoria: 1978 - 1988. São Paulo: Ed. Cortez; 1995.

19. Associação Brasileira de Ensino de Serviço Social. O processo da formação profissional do Assistente Social. Cadernos ABESS 1. São Paulo: Cortez; 1986.

20. Behring E, Boschetti I. Projeto ético-político do Serviço Social e política social. In: Behring E, Boschetti, I. Política Social: fundamentos e história. São Paulo, Cortez; 2006.

21. Faria S. Produção de conhecimento e agenda sócio-profissional no serviço social brasileiro [Tese]. São Paulo: Programa de Pós Graduação em Serviço Social / Pontifícia Universidade Católica de São Paulo, 2003.

22. Kameyama N. A trajetória da produção de conhecimento em Serviço Social: avanços e tendências (1975 - 1997). Cadernos ABESS. 1998; (08).

23. Lukacs G. Ontologia do ser social. Os Princípios Ontológicos Fundamentais de Marx. São Paulo: Ciências Sociais; 1979a.

24. Santos C. Reforma/Revolução - pólos de tensão na constituição do movimento socialista, mimeo, PUC São Paulo, 1998.

25. VV. AA. Serviço Social a caminho do século XXI: o protagonismo ético-político do conjunto

CFESS-CRESS. Serv. Soc. \& Sociedade. 1996; (50). 